\title{
Phosphorus MR spectroscopy shows a tissue specific in vivo distribution of biochemical expression of the G3460A mutation in Leber's hereditary optic neuropathy
}

\author{
R Lodi, V Carelli, P Cortelli, S lotti, M L Valentino, P Barboni, F Pallotti, P Montagna, \\ B Barbiroli
}

Occipital lobe and calf muscle energy metabolism were studied in vivo by magnetic resonance spectroscopy $\left({ }^{31} \mathrm{P}-\mathrm{MRS}\right)$ in four members of a family harbouring the mitochondrial DNA G3460A mutation causing Leber's hereditary optic neuropathy (LHON). Three siblings carried $100 \%$ mutated mitochondrial DNA (homoplasmy), while their mother had coexistence of mutated and wild-type mitochondrial DNA (heteroplasmy). Indices of brain energy metabolism on ${ }^{31}$ P-MRS were abnormal in all subjects examined, but the muscle oxidative phosphorylation rate was normal. These findings indicate a tissue specific distribution of the biochemical expression of the G3460A LHON mutation and suggest that extramitochondrial factors, such as nuclear genes, may influence expression of this mutation in vivo.

eber's hereditary optic neuropathy (LHON), the commonest cause of isolated blindness in young men, is a -maternally inherited form of bilateral acute or subacute loss of central vision associated with retinal ganglion cells and optic nerve degeneration. A mitochondrial DNA point mutation at one of three nucleotide positions (11778, 14484, or 3460 ) is found in the majority of LHON pedigrees. ${ }^{1}$ All three mutations affect genes coding for different subunits of complex I of the mitochondrial respiratory chain. The G3460A mutation affects the NDl subunit and is found in 4-19\% of all LHON patients. ${ }^{1}$ This mutation has been consistently found to result in a $60-80 \%$ reduction in complex I specific activity in a variety of tissues. ${ }^{2-4}$ However, the relation between enzyme activity, oxidative phosphorylation, and the rate of mitochondrial ATP synthesis is still far from clear. Cock et al showed that reduced complex I activity was associated with a normal rate of mitochondrial ATP production in fibroblasts carrying the G3460A mutation. ${ }^{5}$ Similarly, study of another extraneural tissue (skeletal muscle) showed a normal in vivo mitochondrial ATP production rate in a single LHON patient homoplasmic for the G3460A mutation. ${ }^{6}$ Cybrid cell studies suggested that the nuclear background may modulate the expression of the biochemical deficit associated with the G3460A mutation.

To gain insight into the biochemical expression of the G3460A mutation in vivo we used phosphorus magnetic resonance spectroscopy ( $\left.{ }^{31} \mathrm{P}-\mathrm{MRS}\right)$, a sensitive method of evaluating mitochondrial function in intact tissues. ${ }^{89}$ We studied energy metabolism in neural and extraneural tissues in four members of a LHON pedigree harbouring the G3460A mutation.

\section{METHODS}

\section{Patients}

We studied four individuals (I-2, II-1, II-2, and II-3) from a family harbouring the G3460A mutation previously shown to have a reduced complex I activity in platelets (family 4 in Carelli et al). ${ }^{4}$ The proband (II-1) suffered typical LHON at 18 years of age. His visual acuity is now reduced to counting fingers in both eyes, with severe optic atrophy. His twin sisters (II-2, II-3) never complained of any visual disturbance. The proband's mother never complained of visual loss, nor shows optic atrophy on fundoscopic examination. A proband's maternal aunt, now deceased, also suffered LHON in her twenties.

Informed consent was obtained from each patient and from normal volunteers (see below), and the studies were carried out with the approval of the local hospital ethics committee.

\section{Molecular genetic studies}

Total DNA was extracted from multiple tissues (whole blood, leucocyte or platelet enriched pellets, urinary epithelium, and liver biopsy, as shown in table 1) by a standard phenolchloroform method. ${ }^{4}$ Heteroplasmy of mitochondrial DNA was evaluated by polymerase chain reaction (PCR) amplification of a convenient mitochondrial DNA fragment encompassing the G3460A mutation, followed by restriction fragment

Table 1 Mutation load and brain phosphorus magnetic resonance (MR) spectroscopy data

\begin{tabular}{|c|c|c|c|c|c|c|c|c|c|c|}
\hline \multirow[b]{2}{*}{ Case } & \multirow[b]{2}{*}{ Age/sex } & \multicolumn{5}{|c|}{ Mutated mtDNA (\%) } & \multicolumn{4}{|c|}{ Phosphorus MR spectroscopy } \\
\hline & & $\begin{array}{l}\text { Whole } \\
\text { blood }\end{array}$ & Platelets & Leucocytes & $\begin{array}{l}\text { Liver } \\
\text { biopsy }\end{array}$ & $\begin{array}{l}\text { Urinary } \\
\text { epithelium }\end{array}$ & {$[\mathrm{PCr}](\mathrm{mM})$} & {$[\mathrm{Pi}](\mathrm{mM})$} & {$[\mathrm{ADP}](\mu \mathrm{M})$} & $\mathrm{PP}\left(\mathrm{mM}^{-1}\right)$ \\
\hline $1-2$ & $56 / F$ & 56 & 24 & 36 & na & na & 3.30 & 1.28 & 45 & 52 \\
\hline$\|-1$ & $33 / M$ & 100 & 100 & 100 & 100 & 100 & 3.03 & 1.54 & 52 & 38 \\
\hline$\|-2$ & $25 / F$ & 100 & 100 & 100 & na & 100 & 2.78 & 1.58 & 55 & 35 \\
\hline II-3 & $25 / F$ & 100 & na & na & na & 100 & 2.63 & 1.48 & 61 & 33 \\
\hline $\begin{array}{l}\text { Controls } \\
(n=36)\end{array}$ & $\begin{array}{l}\text { Mean (SD) } \\
\text { (range) }\end{array}$ & & & & & & $\begin{array}{l}4.39(0.25) \\
(3.97 \text { to } 4.78)\end{array}$ & $\begin{array}{l}1.31(0.13) \\
(1.02 \text { to } 1.47)\end{array}$ & $\begin{array}{l}29 \text { (2) } \\
(24 \text { to } 33)\end{array}$ & $\begin{array}{l}80(6) \\
(71 \text { to } 98)\end{array}$ \\
\hline
\end{tabular}

na, not available; $\mathrm{PCr}$, phosphocreatine; $\mathrm{Pi}$, inorganic phosphate; $\mathrm{PP}$, phosphorylation potential $(=[\mathrm{ATP}] /[\mathrm{ADP}] \times[\mathrm{Pi}])$. 

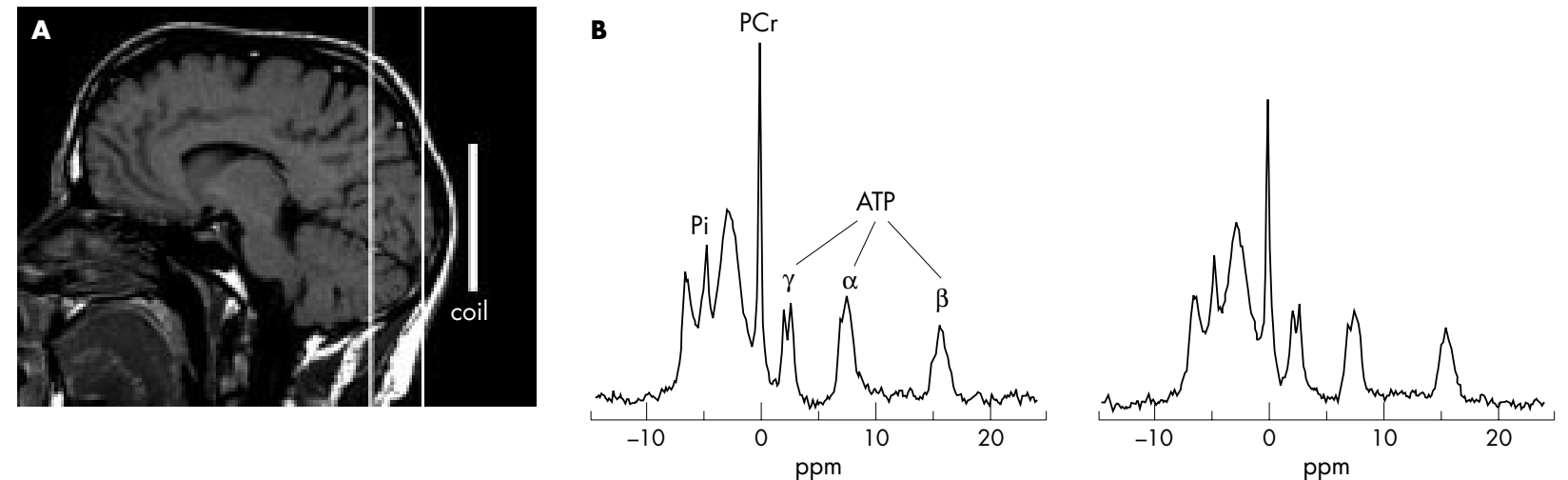

Figure 1 (A) Sagital spin-echo T1 weighted magnetic resonance (MR) image showing the location of the $7.5 \mathrm{~cm}$ diameter surface coil. The region of interest was selected by the DRESS localisation technique for ${ }^{31}$ P-MRS acquisitions. Vertical lines define in the occipital region a 2.5 $\mathrm{cm}$ thick coronal slice. (B) ${ }^{31} \mathrm{P}$ MR spectra (400 free induction decays) from occipital lobes of a healthy volunteer, and case II-1 carrying the 3460/ND1 mtDNA mutation. DRESS, depth resolved surface coil spectroscopy; PCr, phosphocreatine; $\mathrm{Pi}$, inorganic phosphate. The phosphomonoesters peak is located to the left of the Pi peak; the phosphodiesters peak is located between Pi and PCr. The abscissa reports the chemical shift in parts per million (ppm) and the ordinate the relative intensity.

length polymorphism (RFLP) analysis after digestion with the restriction endonuclease BsaHI. ${ }^{4}$

\section{Phosphorus MR spectroscopy}

${ }^{31} \mathrm{P}$-MRS was carried out in a whole body GE 1.5 Tesla Signa system using a $7.5 \mathrm{~cm}$ diameter surface coil.

Brain ${ }^{31} \mathrm{P}$-MRS was done on the occipital lobes by positioning a surface coil on the occipital region after imaging the brain, as previously described. ${ }^{10}$ The DRESS (depth resolved surface coil spectroscopy) localisation technique ${ }^{11}$ was used to avoid any contributions to the signal from neck muscles, skin, and other interposed tissues. On the basis of proton sagittal images of the brain, a $2.5 \mathrm{~cm}$ thick coronal slice was selected and the profile of the sensitivity volume of the $7.5 \mathrm{~cm}$ diameter coil $^{10}$ was routinely overlapped to the images to avoid contamination by the signal of neck muscles, skin, and other interposed tissues (fig lA). The resulting volume of interest can be estimated to be about $90 \mathrm{~cm}^{3}$. The repetition time was $5 \mathrm{~s}$. The flip angle in the selected volume was approximately $30^{\circ}$, and it was not necessary to introduce any correction for saturation effects caused by repetition time. To obtain a signal to noise ratio of 9 to 12 for $\beta$-ATP, 400 free induction decays were accumulated. A computerised curve fitting program was used to quantify the individual peaks of the spectrum.

Phosphocreatine (PCr) and inorganic phosphate (Pi) concentrations were calculated by assuming a cytosolic [ATP] of $3 \mathrm{mM} .{ }^{10}$ In order to determine the phosphorylation potential $(\mathrm{PP}=[\mathrm{ATP}] /([\mathrm{ADP}] \times[\mathrm{Pi}])$, a global index of readily available free energy in the cell, ${ }^{12}$ free cytosolic ADP concentration was calculated from the creatine kinase equilibrium. $^{13}$

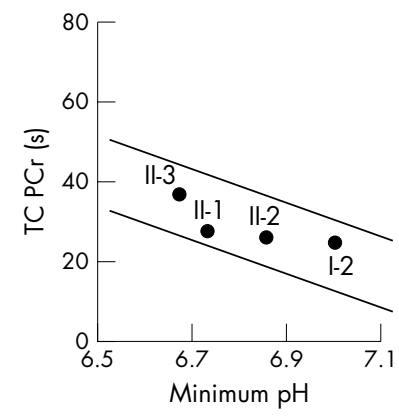

Figure 2 Rate of phosphocreatine $(\mathrm{PCr}$ ) resynthesis after exercise in the four subjects carrying the A3460G m+DNA mutation. In view of the influence of the cytosolic $\mathrm{pH}$ on the rate of $\mathrm{PCr}$ resynthesis after exercise, the time constant (TC) of $\mathrm{PCr}$

recovery is plotted against the minimum $\mathrm{pH}$ reached in the postexercise period. ${ }^{14}$ The two lines represent the $95 \%$ confidence interval defined in healthy subjects.
Muscle ${ }^{31} \mathrm{P}$-MRS was performed on the right calf muscle by the pulse and acquire technique (repetition time of five seconds) at rest, during in-magnet aerobic incremental exercise of plantar flexion as previously described. ${ }^{14}$ Postexercise spectra were collected for five minutes, with a time resolution of 10 seconds during the first 60 seconds and 30 seconds thereafter. The limits of all the peaks were marked manually on each spectrum after phasing, and areas calculated between the limits. ${ }^{14}$ Muscle mitochondrial ATP production was assessed by measuring the rate of entirely oxidative $\mathrm{PCr}$ resynthesis during recovery. ${ }^{14}$ The rate of $\mathrm{PCr}$ resynthesis was calculated from the monoexponential equation best fitting the experimental points, and reported as time constants. Intracellular $\mathrm{pH}$ was calculated from the chemical shift of Pi relative to PCr.

Control subjects were healthy volunteers: $\mathrm{n} 36$ (mean (SD) age 37 (17) years) for brain studies, and n 35 (38 (16) years) for skeletal muscle studies. Data are presented as mean (SD). Individual results were taken as abnormal when they fell outside the normal range.

\section{RESULTS}

All tissues examined were homoplasmic for the G3460A mutation in the index case (II-1) and in his twin sisters (II-2 and II-3), but their mother (I-2) showed a variable degree of heteroplasmy in the examined tissues (table 1). Brain indices of mitochondrial function such as [PCr], free [ADP], and PP were abnormal in all individuals carrying the G3460A mutation (table 1, fig 1B). Occipital lobe [Pi] was within the normal range only in case I-2. We do not know the load of mutated mitochondrial DNA in the brain of case I-2. However, the milder degree of brain bioenergetic impairment found in case I-2 compared with her offspring suggests the presence of some degree of heteroplasmy in her brain, which in turn would modulate the extent of the energy metabolism deficit (table 1). The rate of $\mathrm{PCr}$ postexercise resynthesis was within normal range in all four subjects carrying the G3460A mutation (fig 2).

\section{DISCUSSION}

Our observations indicate that the biochemical expression of the G3460A mitochondrial DNA mutation in vivo is tissue specific. We found a severe defect of brain bioenergetics in both heteroplasmic and homoplasmic individuals carrying the 
G3460A mitochondrial DNA mutation, but we could not demonstrate an impairment of skeletal muscle mitochondrial oxidative metabolism in any subject. All subjects apart from case I-2 were homoplasmic for the G3460A mitochondrial DNA mutation. Muscle biopsy was not performed in these LHON patients and we do not know the level of mutated mitochondrial DNA in their skeletal muscle. However, at least for the three siblings in the second generation there is consistent evidence that they are homoplasmic mutant in all tissues examined, suggesting that the same probably also applies to skeletal muscle or any other tissue. Thus it seems very unlikely that normal muscle ATP production in these cases could be related to heteroplasmic mitochondrial DNA mutation. The proband's mother showed heteroplasmic mitochondrial DNA in blood cells and-considering the rarity of skewed segregation among tissues in $\mathrm{LHON}^{1}$ - it is conceivable that a fairly similar mutant load would be present in her skeletal muscle.

There is a complex relation between mitochondrial DNA mutations, respiratory chain enzyme specific activity, and the rate of mitochondrial ATP synthesis. The role played by nuclear background has recently been underscored by cybrid cell studies. The expression of defective complex I specific activity associated with the G3460A mutation was modulated by changing the nuclear background of the cybrid cell system used in one study. ${ }^{7}$ Similarly, the comparison of respiratory function between LHON lymphoblast cell lines and lymphoblast derived cybrids harbouring each of the three LHON pathogenic mutations showed differences related to the change in nuclear background. ${ }^{15}$ These observations also seem to apply to mitochondrial DNA mutations in tRNA genes. ${ }^{916} 17$

Previous in vivo ${ }^{31} \mathrm{P}$-MRS studies have shown that the rate of mitochondrial ATP production is severely impaired in the skeletal muscle of subjects carrying the G11778A LHON mitochondrial DNA mutation, ${ }^{6810}$ and to a lesser extent in those carrying the T14484C mutation. ${ }^{6}$ However, complex I enzymatic assays revealed normal ${ }^{4}$ or mildly reduced ${ }^{15}$ activity with the G11778A mutation, and unaltered complex I activity with the T14484C mutation. ${ }^{15}{ }^{18}$ In a previous ${ }^{31} \mathrm{P}$-MRS study of three subjects carrying the 3460 mutant DNA $^{6}$ we showed a negative correlation between percentage of mutated mitochondrial DNA and the rate of skeletal muscle mitochondrial ATP production, measured - as in this study - from the rate of PCr resynthesis after exercise. However, the rate of mitochondrial ATP production was within the normal range in all subjects, ${ }^{6}$ indicating a very small effect of the 3460 mitochondrial DNA mutation on the modulation of the rate of muscle mitochondrial ATP production in vivo.

The relation between primary LHON mutations and complex I dysfunction is still debated, ${ }^{1}$ and various factors, of both mitochondrial and nuclear origin, may play a role in their biochemical expression in vivo.

We provided in vivo evidence of a tissue specific distribution of the biochemical expression of the G3460A LHON mutation which is associated with mitochondrial dysfunction in the occipital lobes, but normal oxidative metabolism in an extraneural tissue (skeletal muscle). This finding-and those of another recent in vivo study investigating the A3243G mitochondrial DNA mutation"-supports the role of the nuclear genetic environment in the biochemical expression of mitochondrial DNA mutations in vivo. Our observations may be important in understanding the molecular mechanisms responsible for the variable penetrance of LHON, and for the fact that its clinical expression is highly restricted to retinal ganglion cells and the optic nerve; it appears that these tissues may express the oxidative phosphorylation deficit produced by specific mitochondrial DNA mutations more severely than other tissues.

\section{ACKNOWLEDGEMENTS}

This work was supported by CNR target project "Biotechnology", grant No 97.01029.PF49EU, by Biomed 2 grant No PL950861; BMH-4-
CT-0861, by CNR grant No 125C96/3132-96/11974, and by Fondazione Cassa di Risparmio in Bologna grant.

\section{Authors' affiliations}

R Lodi, S lotti, B Barbiroli, Dipartimento di Medicina Clinica e Biotecnologia Applicata "D Campanacci", University of Bologna, Bologna, Italy

V Carelli, M L Valentino, P Montagna, Istituto di Clinica Neurologica, University of Bologna

P Cortelli, Dipartimento di Patologia Neuropsicosensoriale, University of Modena, Modena, Italy

P Barboni, Dipartimento di Oculistica, "Centro Salus", Bologna, Italy

F Pallotti, College of Physicians and Surgeons, Columbia University,

New York, USA

Correspondence to: Dr R Lodi, Dipartimento di Medicina Clinica e Biotecnologia Applicata "D Campanacci", Universita' di Bologna, Policlinico S Orsola, Via Massarenti 9, 40138 Bologna, Italy; lodi@med.unibo.it

Received 31 October 2001

In revised form 16 January 2002

Accepted 24 January 2002

\section{REFERENCES}

1 Howell N. Human mitochondrial diseases: answering questions and questioning answers. Int Rev Cytol 1999;186:49-116.

2 Howell N, Bindoff LA, McCullough DA, et al. Leber's hereditary optic neuropathy: identification of the same mitochondrial NDI mutation in six pedigrees. Am J Hum Genet 1991;49:939-50.

3 Majander A, Huoponen K, Savontaus M-L, et al. Electron transfer properties of NADH:ubiquinone reductase in the NDI/3460 and the ND4/1 1778 mutations of the Leber hereditary optic neuroretinopathy (LHON). FEBS Lett 1991;292:289-92.

4 Carelli V, Ghelli A, Ratta $M$, et al. Leber's hereditary optic neuropathy: biochemical effect of 11778 /ND4 and 3460/ND1 mutations and correlation with the mitochondrial genotype. Neurology 1997; 48: 1623-32.

5 Cock HR, Cooper JM, Schapira AHV. Functional consequences of the 3460-bp mitochondrial DNA mutation associated with Leber's hereditary optic neuropathy. J Neurol Sci 1999;165:10-17.

6 Lodi R, Taylor DJ, Tabrizi SJ, et al. In vivo skeletal muscle mitochondrial function in Leber's hereditary optic neuropathy assessed by $31 \mathrm{P}$ magnetic resonance spectroscopy. Ann Neurol 1997;42:573-9.

7 Cock HR, Tabrizi SJ, Cooper JM, et al. The influence of nuclear background on the biochemical expression of 3460 Leber's hereditary optic neuropathy. Ann Neurol 1998;44:187-93

8 Lodi R, Montagna P, Cortelli P, et al. "Secondary" 4216/NDI and 13708/ND5 Leber's hereditary optic neuropathy mitochondrial DNA mutations do not further impair in vivo mitochondrial oxidative metabolism when associated with the 11778 /ND4 mitochondrial DNA mutation. Brain 2000; 123:1896-902.

9 Chinnery PF, Taylor DJ, Brown DT, et al. No correlation between muscle A3243G mutation load and mitochondrial function in vivo. Neurology 2001, 56:1101-4.

10 Barbiroli B, Montagna P, Cortelli P, et al. Defective brain and muscle energy metabolism shown by in vivo ${ }^{31} \mathrm{P}$ magnetic resonance spectroscopy in non-affected carriers of 11778 mitochondrial DNA mutation. Neurology 1995:45:1364-9.

11 Bottomly PA, Foster TH, Darrow RD. Depth-resolved surface-coil spectroscopy (DRESS) for in vivo ${ }^{1} \mathrm{H},{ }^{31} \mathrm{P}$, and ${ }^{13} \mathrm{C}$ NMR. J Magn Reson 1984;59:338-42

12 Veech RL, Lawson JWR, Cornell NW, et al. Cytosolic phosphorylation potential. J Biol Chem 1979;254:6538-47.

13 Degani H, Alger J, Shulman R, et al. ${ }^{31} \mathrm{P}$ magnetization transfer studies of creatine kinase kinetics in living rabbit brain. Magn Reson Med 1987;5:1-12.

14 lotti S, Lodi R, Frassineti $C$, et al. In vivo assessment of mitochondrial functionality in human gastrocnemius muscle by $31 \mathrm{P}$ MRS. The role of $\mathrm{pH}$ in the evaluation of phosphocreatine and inorganic phosphate recoveries from exercise. NMR Biomed 1993;6:248-53

15 Brown MD, Trounce IA, Jun AS, et al. Functional analysis of lymphoblast and cybrid mitochondria containing the 3460,11778 , or 14484 Leber's hereditary optic neuropathy mitochondrial DNA mutation. J Biol Chem 2000;275:39831-6.

16 Dunbar DR, Moonie PA, Jacobs HT, et al. Different cellular backgrounds confer a marked advantage to either mutant or wild-type mitochondrial genomes. Proc Natl Acad Sci USA 1995:92:6562-6.

17 Hao H, Morrison LE, Moraes CT. Suppression of a mitochondrial tRNA gene mutation phenotype associated with changes in the nuclear background. Hum Mol Genet 1999;8:1117-24.

18 Carelli V, Ghelli A, Bucchi L, et al. Biochemical features of mitochondrial DNA 14484 (ND6/M64V) point mutation associated with Leber's hereditary optic neuropathy. Ann Neurol 1999;45:320-8. 